\title{
Validation Evidence of the Motivation for Teaching Scale in Secondary Education
}

\author{
Ángel Abós, Javier Sevil, José Martín-Albo, Alberto Aibar and Luis García-González \\ Universidad de Zaragoza (Spain)
}

\begin{abstract}
Grounded in self-determination theory, the aim of this study was to develop a scale with adequate psychometric properties to assess motivation for teaching and to explain some outcomes of secondary education teachers at work. The sample comprised 584 secondary education teachers. Analyses supported the five-factor model (intrinsic motivation, identified regulation, introjected regulation, external regulation and amotivation) and indicated the presence of a continuum of self-determination. Evidence of reliability was provided by Cronbach's alpha, composite reliability and average variance extracted. Multigroup confirmatory factor analyses supported the partial invariance (configural and metric) of the scale in different sub-samples, in terms of gender and type of school. Concurrent validity was analyzed by a structural equation modeling that explained $71 \%$ of the work dedication variance and $69 \%$ of the boredom at work variance. Work dedication was positively predicted by intrinsic motivation $(B=.56, p<.001)$ and external regulation $(B=.29, p<.001)$ and negatively predicted by introjected regulation $(B=-.22, p<.001)$ and amotivation $(\beta=-.49, p<.001)$. Boredom at work was negatively predicted by intrinsic motivation $(\beta=-.28, p<.005)$ and positively predicted by amotivation $(B=.68, p<.001)$. The Motivation for Teaching Scale in Secondary Education (Spanish acronym EME-ES, Escala de Motivación por la Enseñanza en Educación Secundaria) is discussed as a valid and reliable instrument. This is the first specific scale in the work context of secondary teachers that has integrated the five-factor structure together with their dedication and boredom at work.
\end{abstract}

Received 28 December 2016; Revised 15 March 2018; Accepted 16 March 2018

Keywords: motiviation, self-determination, teaching, validation.

Motivation for teaching can be understood as how teachers behave with respect to their teaching work. It is a factor that may intervene directly in the teachinglearning process and that may subsequently affect education quality (Roth, Assor, Kanat-Maymon, \& Kaplan, 2007; Viseu, de Jesus, Rus, \& Canavarro, 2016). Motivation for teaching seems crucial for optimal professional development, given that highly motivated teachers are characterized by greater engagement (Cheon, Reeve, Yu, \& Jang, 2014), lower burnout (van den Berghe et al., 2014) and greater work dedication (Thoonen, Sleegers, Oort, Peetsma, \& Geijsel 2011). Motivated teachers also have a more progressive and flexible view of changes in the educational system (Han \& Yin, 2016). In addition, motivation for teaching can enhance their students' motivation (Pelletier, Séguin-Lévesque, \& Legault, 2002). However, despite evidence that supports its relevance, teachers show higher levels of stress and burnout than other professions (Kinman, Wray, \& Strange, 2011), and secondary education teachers are the ones that express less satisfaction with their work (Anaya \& López, 2014).

Correspondence concerning this article should be addressed to Ángel Abós. Departamento de Expresión Musical Plástica y Corporal de Universidad de Zaragoza. Plaza Universidad, 3. 22001 Huesca (Spain).

E-mail: aabosc@unizar.es
Traditionally, studies of teachers' motivation have been underestimated in the research community, compared with studies of students' motivation (Viseu et al., 2016). However, over the last two decades, the worsening of working conditions together with the continuous changes in education laws has led many researchers to study this subject in greater depth (Watt \& Richardson, 2015). The first studies that analyzed teachers' motivation looked for the reasons why the teaching profession was chosen (Han \& Yin, 2016). However, over the last ten years, studies that seek an explanation to motivation for teaching, as well as the causes and outcomes of this motivation, have increased (Viseu et al., 2016). This increasing scientific interest in motivation for teaching has been addressed from different theoretical frameworks (e.g., expectancy-value theory or achievement goal theory) (Watt \& Richardson, 2015). However, the self-determination theory (SDT) (Deci \& Ryan, 1985) is the most commonly used framework to analyze teachers' motivational processes (e.g., Cheon et al., 2014; Roth et al., 2007; Thoonen et al., 2011).

How to cite this article:

Abós, A., Sevil, J., Martín-Albo, J., Aibar, A., \& García-González, L. (2018). Validation evidence of the Motivation for Teaching Scale in Secondary Education. The Spanish Journal of Psychology, 21. e9. Doi: $10.1017 /$ sjp.2018.11 


\section{Theoretical Framework: SDT}

According to SDT, human behavior can be amotivated, extrinsically motivated or intrinsically motivated. The various types of motivation can predict a number of cognitive, affective, and behavioral outcomes in teachers (Roth et al., 2007). This process can be studied throughout a continuum that explains the different behavioral regulations, from the least internalized to the most self-determined. Thus, the least self-determined type of motivation, amotivation, is characterized by a lack of competence and intention to engage in a conduct, together with a lack of expectancy to reach the desired result (e.g., teachers who do not understand why they should continue teaching as they think that the work they do is useless) (Deci \& Ryan, 1985).

Going from a lower to a higher level of selfdetermination, extrinsic motivation can be differentiated into external, introjected, identified, and integrated regulation (Deci \& Ryan, 1985). External regulation refers to carrying out an activity to achieve rewards or to avoid punishment (e.g., teachers who teach because they get longer holidays and a good salary). Introjected regulation characterizes those conducts carried out to avoid feelings of blame (e.g., teachers who prepare the classes so as not to feel worse about themselves). Identified regulation reflects those tasks where individuals place value on what they do because they believe that it may be important (e.g., teachers who believe their work may be important for their own personal and professional development, and for that of their students). This continuum of self-determination is followed by integrated regulation, although some previous SDT-based research studies recommend not examining it because of the difficulty in distinguishing between identified and integrated regulations using self-report scales (e.g., Blais, Lachance, Vallerand, Brière, \& Riddle, 1993; Roth et al., 2007). Finally, intrinsic motivation is the most self-determined form of motivation. This is characterized by a lack of external reinforcements to develop a task, the main reason being inherent satisfaction derived from the teaching activity (e.g., teachers who do their work for the pleasure it produces for them) (Deci \& Ryan, 1985). Based on previous research (e.g., Joe, Hiver, \& Al-Hoorie, 2017), in this study, the term less self-determined forms of motivation has been used to refer to introjected and external regulations, and the term more self-determined forms of motivation to refer to intrinsic motivation and identified regulation.

A substantial body of research, grounded in SDT, has shown that more self-determined forms of motivation can facilitate positive outcomes such as teaching engagement (Cheon et al., 2014) and teachers' intention to continue learning and to get involved in innovation projects (Gorozidis \& Papaioannou, 2014; Thoonen et al., 2011) as well as to avoid exhaustion (Fernet, Guay, Senécal, \& Austin, 2012; Roth et al., 2007). There are, in turn, studies that have addressed the negative outcomes of teachers' less self-determined forms of motivation and amotivation, finding a positive relationship with burnout (Fernet, Senécal, Guay, Marsh, \& Dowson, 2008), teaching exhaustion (Eyal \& Roth, 2011), and with their lack of interest in participating in training and in implementing innovations (Gorozidis \& Papaioannou, 2014). Likewise, Fernet et al. (2008) found a negative relationship between less self-determined forms of motivation and amotivation, and teachers' self-efficacy.

\section{Existing measures of teachers' self-determined motivation}

Conversely, some SDT-based studies that have evaluated teachers' self-determined motivation toward their work (e.g., Pelletier et al., 2002) have done so through general working context-oriented measures, such as the Work Motivation Inventory (Blais et al., 1993) or the Work Extrinsic and Intrinsic Motivation Scale (Tremblay, Blanchard, Taylor, Pelletier, \& Villeneuve, 2009). This type of assessment may be too universal to obtain an accurate vision of motivation for teaching and it may have been a potential limitation in the findings (Fernet et al., 2008; Roth et al., 2007). To overcome this limitation, Roth et al. (2007), following Ryan and Connell (1989) and Pelletier et al. (2002), developed the Autonomous Motivation for Teaching. Likewise, based on the Dutch version (Vansteenkiste, Sierens, Soenens, Luyckx, \& Lens, 2009) of the Self-Regulation QuestionnaireAcademic (SRQA) (Ryan \& Connell, 1989), Soenens, Sierens, Vansteenkiste, Dochy and Goossens (2012) carried out an adaptation of this scale to the teaching context to measure motivation for teaching. Both instruments, that is, the one proposed by Roth et al. (2007) and the one proposed by Soenens et al. (2012), comprised 16 items that assessed four types of motivation (external, introjected, identified and intrinsic), presenting adequate psychometric properties. However, the main limitation of these instruments was that they were not validated within the teaching context. The sample size used was limited and the reliability analyses were not very high, some factors being below .70 . Likewise, these two instruments did not take the amotivation subscale into account to assess motivation for teaching.

Based on the six specific tasks that comprise teaching work (class preparation, teaching, student evaluation, classroom management, administrative tasks, and complementary tasks), Fernet et al. (2008) developed the Work Task Motivation Scale for Teachers (WTMST), which measures amotivation for teaching. It also 
evaluates the other factors included in the Autonomous Motivation for Teaching scale (Roth et al., 2007) and in the scale proposed by Soenens et al. (2012). The only disadvantage is the number of items $(90,15$ in each task), which means that its full application is very tedious.

However, the WTMST, in a general and shortened version on teaching work, with 15 items, has been validated in the context of different countries, such as Canada (Fernet et al., 2012), Greece (Gorozidis \& Papaioannou, 2012) and Spain (Ruiz-Quiles, MorenoMurcia, \& Vera, 2015). A sample of 161 teachers was used for this short version of the scale in Spanish, going from Primary School through to University. However, there is scientific literature that argues the existence of specific demands in teaching work at each educational stage (Anaya \& López, 2014). For example, teaching younger students may require less cognitive demands for teachers (Burke \& Greenglass, 1989). In addition, there are studies that hold that secondary students have less interest, so motivating them can be a very demanding task for teachers (Antoniou, Ploumpi, \& Ntalla, 2013). Besides, problems of indiscipline, aggressions, insults and constant confrontations with teachers are accentuated in secondary education (Otero-López, Castro, Villardefrancos, \& Santiago, 2009). These increasing demands in secondary education could influence teachers' responses regarding their motivation for teaching.

\section{Objective and hypothesis}

To our knowledge, grounded in SDT, there is no instrument in Spanish that assesses motivation for teaching in the specific stage of secondary education ${ }^{1}$. Moreover, the current study adds further evidence by examining the role of teachers' motivation in dedication and boredom at work. The general purpose of the study was to develop a reliable and valid scale, with adequate psychometric properties, to evaluate motivation for teaching in secondary education. Moreover, this scale could help explain some work outcomes. Thus, three hypotheses were put forward.

First, in line with previous validation studies on motivation for teaching scales (Fernet et al. 2008; Fernet et al., 2012; Gorozidis \& Papaioannou, 2012; RuizQuiles et al., 2015), it is hypothesized that the EME-ES (Spanish acronym for Motivation for Teaching Scale

\footnotetext{
${ }^{1}$ Secondary education, in the Spanish educational system, includes two levels. The first one is called Compulsory Secondary Education (Spanish acronym, ESO) and consists of four academic years. The second is called Baccalaureate and consists of two academic years that allow access to vocational education and training, and to the university. Teachers who work in secondary education can teach in ESO and Baccalaureate.
}

in Secondary Education/Escala de Motivación por la Enseñanza en Educación Secundaria) will adapt to the five-factor structure proposed by the SDT, showing adequate psychometric properties and invariance across gender and type of school. Recent studies recommend reporting invariance (at least metric; Cheung \& Rensvold, 2002) in factors such as gender, age or other important socio-demographic characteristics such as type of school (e.g., Ayman \& Korabik, 2010; Lukaszewski \& Stone, 2012). Indeed, past studies have shown that female teachers present higher levels of intrinsic motivation and identified regulation, and lower levels of introjected and external regulation and amotivation toward teaching than their male counterparts (Fernet et al., 2008; Nie, Chua, Yeung, Ryan, \& Chan, 2015). Several studies have also suggested that the type of school could affect teachers' work motivation processes, particularly in Spain (Gil-Flores, 2016; Latorre \& Saéz, 2009). For example, Latorre \& Sáez (2009) showed that teachers in state schools reported less motivation than teachers in non-state schools. Therefore, to evaluate teacher motivation, developing an invariant scale in terms of gender and type of school (Cheung \& Rensvold, 2002) seems to be necessary.

Second, according to the SDT and previous studies that have analyzed more self-determined forms of motivation and teachers' outcomes (e.g., Cheon et al., 2014; Fernet et al., 2012; Gorozidis \& Papaioannou, 2014; Roth et al., 2007; Thoonen et al., 2011), it is hypothesized that intrinsic motivation and identified regulation will significantly and positively affect work dedication, and will significantly and negatively affect boredom at work.

Last, but not least, grounded in SDT and past studies that have analyzed less self-determined forms of motivation, amotivation and teachers' outcomes (e.g., Eyal \& Roth, 2011; Fernet et al., 2008; Fernet, et al., 2012; Gorozidis \& Papaioannou, 2014), it is hypothesized that introjected regulation, external regulation and amotivation will significantly and positively affect boredom at work, and will significantly and negatively affect work dedication.

\section{Method}

\section{Participants}

Table 1 shows the final distribution of the sample, which comprises 584 teachers $\left(M_{\text {age }}=45.04 ; S D=8.97\right)$ with 17.55 years' average working experience $(S D=$ 10.26). Simple random sampling was used, ensuring the representativeness of the sample for the Aragon district-territory (Spain). The inclusion criteria were: Having worked as a teacher during the 2014/2015 academic year at a Secondary School in Aragon, and having answered all the questions. 
Table 1. Characteristics of the Final Study Sample $(n=584)$

\begin{tabular}{|c|c|c|c|c|c|c|}
\hline & & \multirow[b]{2}{*}{$N$} & \multicolumn{2}{|l|}{ Age } & \multicolumn{2}{|c|}{ Experience } \\
\hline & & & $M$ & $S D$ & $M$ & $S D$ \\
\hline \multirow[t]{2}{*}{ Gender } & Male & 254 & 45.97 & 9.06 & 18.73 & 10.71 \\
\hline & Female & 330 & 44.32 & 8.84 & 16.65 & 8.83 \\
\hline \multirow[t]{2}{*}{ Type of school } & State & 416 & 45.34 & 8.70 & 17.83 & 10.03 \\
\hline & Non-State & 168 & 44.15 & 8.88 & 16.05 & 9.43 \\
\hline
\end{tabular}

\section{Procedure}

First, the consent of the Aragon Education Council was obtained, which also provided information about contact details of the secondary teachers in Aragon. Online data collection, through e-mails and web-based surveys, was carried out to access all schools in Aragon, preserving participant anonymity. The virtual platform was reviewed by the group of experts who solved errors of understanding and operation before it was launched. After approval, each teacher received an e-mail with a brief explanation of the study, the link for them to access the questionnaire and the contact details of the main researcher in case they wanted to obtain more information. The virtual platform was active for 30 days.

\section{Variables and instruments}

\section{Motivation for teaching}

The Motivation for Teaching Scale in Secondary Education (henceforth, Spanish acronym, EME-ES) (Table 2) was devised to measure motivation for teaching. This scale was headed: "I get involved in teaching, because.../ Me involucro en la enseñanza, porque..." followed by 19 items that measure five factors: Intrinsic motivation, identified regulation, introjected regulation, external regulation and amotivation. All the factors comprised four items except for amotivation (three). Responses were provided on a 5-point Likert-type scale ranging from 1 (Strongly Disagree/Totalmente en desacuerdo) to 5 (Strongly Agree/Totalmente de acuerdo).

Two previously validated instruments were used to devise the EME-ES. To measure intrinsic and extrinsic motivation (integrated, identified and external regulation) for teaching, the Spanish translation of an adaptation of the SRQA (Ryan \& Connell, 1989), proposed by Soenens et al. (2012), was used. This version showed adequate psychometric properties in previous studies with 317 Belgian teachers (Soenens et al., 2012). In parallel, due to the lack of an amotivation factor in this questionnaire, the items that measure this factor in the Work Extrinsic and Intrinsic Motivation Scale (Tremblay et al., 2009) were selected, adapting them to the teaching work context.
For the Spanish adaptation and translation, the guidelines of the International Test Commission (ITC) (Muñiz, Elosua, \& Hambleton, 2013) were followed. Firstly, a group of experts in SDT with a high English language level carried out the initial translation of each of the items separately into Spanish. Then a native bilingual translator translated the questionnaire into the original language to ensure that the items maintained the structure and meaning of the original scales. Finally, the items were submitted to a content validity assessment by four experts with extensive training in SDT and the validation of instruments, who estimated the adaptation of the items to the constructs they referred to, and adapted them to the Secondary Education teaching work context. Furthermore, the items were formulated in a positive manner, except for the amotivation factor, as the nature of the amotivation construct is negative (i.e., amotivation reflects a lack of motivation). Therefore, a wording in the same vein (i.e., negative) may help understand the amotivation items (Muñiz et al., 2013).

\section{Work dedication}

The five items corresponding to the dedication factor (e.g., "I am enthusiastic about my work") from the Spanish version of the Utrecht Work Engagement Scale (Schaufeli, Martínez, Marques-Pinto, Salanova, \& Bakker, 2002) were used to measure work dedication. Responses were provided on a 6-point Likerttype scale ranging from 0 (Never) to 6 (Always). This subscale showed adequate psychometric properties $(\alpha \geq .86)$ in previous studies with teachers (Høigaard, Giske, \& Sundsli, 2012). In the current study, a confirmatory factor analysis (CFA) was performed showing adequate goodness-of-fit $\left(\chi^{2}=18.047 ; d f=5\right.$; $\chi^{2} / d f=3.609, p<.001 ;$ RMSEA = .067; CFI = .987; TLI $=.975)$.

\section{Boredom at work}

The four items that measure boredom at work (e.g., "I feel my work is mechanical and routine") from the Spanish version of the Burnout Clinical Subtype Questionnaire (Montero-Marín \& García-Campayo, 2010) were used to measure boredom at work. Responses were registered on a 7-point Likert scale ranging from 1 (Totally disagree) to 7 (Totally agree). In the present study, a CFA was performed showing adequate goodness-offit $\left(\chi^{2}=6.285 ; d f=2 ; \chi^{2} / d f=3.142, p<.001 ;\right.$ RMSEA = .061; $\mathrm{CFI}=.991 ; \mathrm{TLI}=.973)$.

\section{Data analysis}

A descriptive analysis of the items was conducted for the construct validity of the EME-ES. Then, a CFA was 
Table 2. Item Descriptive Statistics, Asymmetry, Kurtosis and Standardized Values of the EME-ES

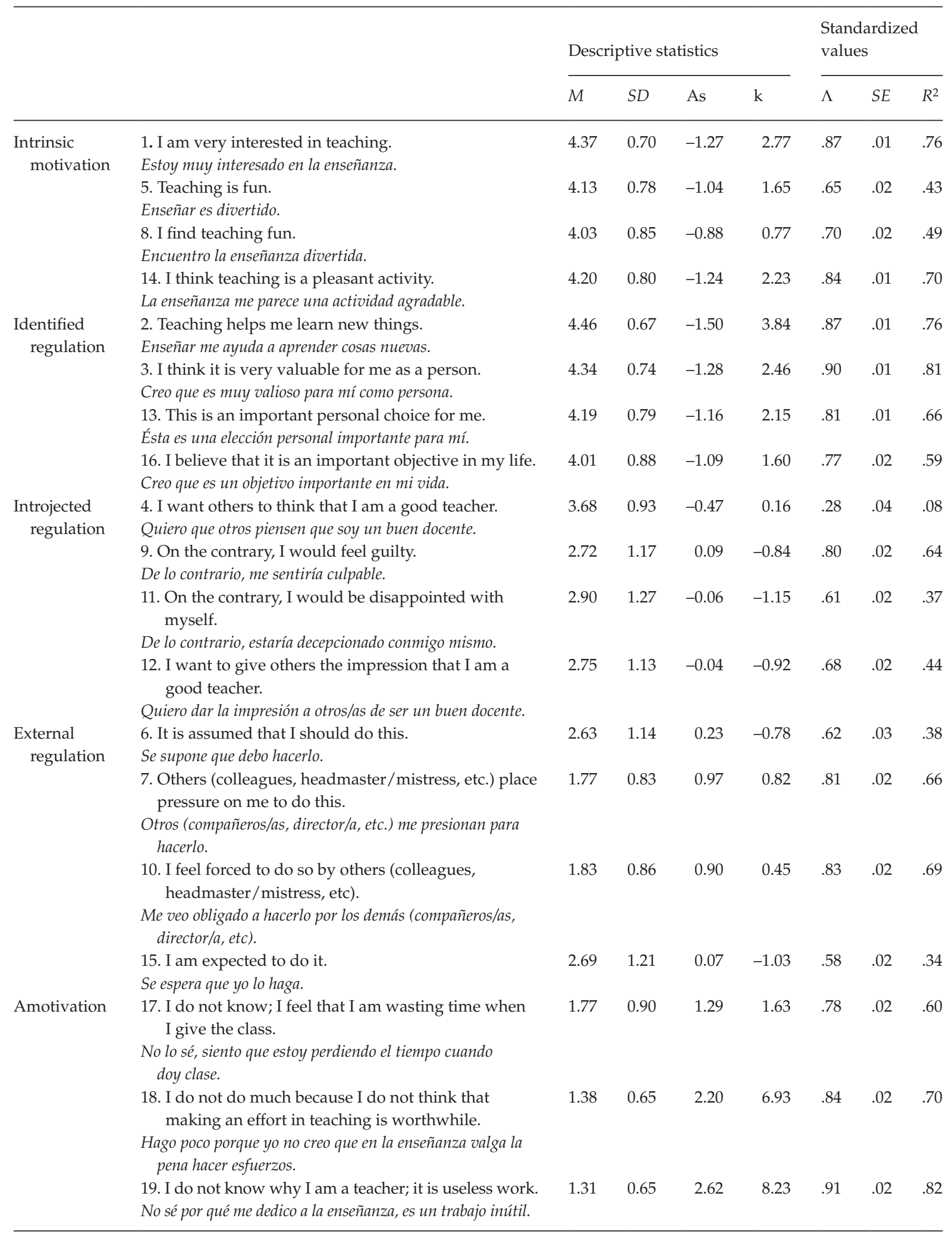

Note: As = Asymmetry; $\mathrm{k}=$ Kurtosis; $\lambda=$ Standardized factor loadings; $S E=$ Standard error; $R^{2}=$ Explained variance. All parameters were significant $(p<.001)$. The standardized values of the 19 items correspond to Model 2. In italics the items of the original version of the EME-ES created in Spanish. 
Table 3. Descriptive Statistics, Asymmetry, Kurtosis, Reliability and Latent Correlations for the Study Variables

\begin{tabular}{|c|c|c|c|c|c|c|c|c|c|c|c|c|}
\hline & Range & $M$ & $S D$ & As & $\mathrm{k}$ & 1 & 2 & 3 & 4 & 5 & 6 & 7 \\
\hline 1. Intrinsic motivation & $1-5$ & 4.18 & 0.63 & -0.93 & 1.39 & 1 & $.91^{* *}$ & .09 & $-.37^{* *}$ & $-.73^{* *}$ & $.60^{* *}$ & $-.53^{* *}$ \\
\hline 2. Identified regulation & $1-5$ & 4.25 & 0.62 & -1.10 & 2.11 & & 1 & $.15^{*}$ & $-.26^{* *}$ & $-.66^{* *}$ & $.55^{* *}$ & $-.48^{* *}$ \\
\hline 3. Introjected regulation & $1-5$ & 3.01 & 0.80 & -0.05 & -0.44 & & & 1 & $.66^{* *}$ & $.26^{* *}$ & -.02 & $.04^{*}$ \\
\hline 4. External regulation & $1-5$ & 2.23 & 0.78 & 0.18 & -0.39 & & & & 1 & $.67^{* *}$ & $-.19^{* *}$ & $.26^{* *}$ \\
\hline 5. Amotivation & $1-5$ & 1.49 & 0.60 & 1.48 & 2.91 & & & & & 1 & $-.53^{* *}$ & $.59^{* *}$ \\
\hline 6. Work dedication & $0-6$ & 4.17 & 1.12 & -0.57 & -0.75 & & & & & & 1 & $-.54^{* *}$ \\
\hline 7. Boredom at work & $1-7$ & 2.22 & 1.20 & 1.05 & 1.18 & & & & & & & 1 \\
\hline Cronbach's Alpha $(\alpha)$ & & & & & & .82 & .82 & .68 & .76 & .73 & .90 & .90 \\
\hline CR & & & & & & .85 & .91 & .70 & .81 & .88 & .92 & .94 \\
\hline AVE & & & & & & .59 & .70 & .39 & .52 & .71 & .69 & .79 \\
\hline
\end{tabular}

Note: ${ }^{*} p<.005 ;{ }^{* *} p<.001$.

performed using the weighted least squares mean and variance adjusted estimator (WLSMV). This estimator was selected because multivariate normality deviations are common in social sciences, and, using the standard maximum likelihood (ML) estimation method, they increase the value of chi-square $\left(\chi^{2}\right)$ and underestimate that of standard errors (Finney \& DiStefano, 2006). The self-determination continuum was verified by latent correlations between the five factors of the EME-ES. Later on, three multi-group CFA were conducted to test the invariance of the measurement model, verifying stability in different groups (odd and even subsamples, gender, and type of school). Finally, reliability was verified, using Cronbach's alpha coefficient, as well as the composite reliability (CR) and the average variance extracted (AVE) coefficient through factor loadings and the measurement errors originating from the CFA. Regarding concurrent validity, a latent correlation analysis was conducted between the EME-ES factors and the CFA factors of work dedication and boredom at work. Afterwards, a structural equation modeling (SEM) was carried out to verify this theoretical sequence. The statistical software programs used were Mplus 7.0, SPSS 22 and AMOS 19.

Because the chi-square $\left(\chi^{2}\right)$ could be oversensitive to sample size, the assessment of the (CFA and SEM) models relied on the following goodness-of-fit indices: The root mean square error of approximation (RMSEA), the comparative fit index (CFI), the Tucker Lewis index (TLI) and the expected cross-validation index (ECVI). With respect to RMSEA, values of .08 or less are considered as acceptable (Marôco, 2014), and with respect to CFI and TLI, values greater than .90 and .95 indicate appropriate and excellent fit to the data, respectively. Finally, lower values of ECVI indicate better fit (Marôco, 2014).

\section{Results}

\section{Construct validity}

\section{Item descriptive statistics}

The item descriptive statistics are shown in Table 2, with means of between 1.31 (Item 19) and 4.46 (Item 2). Although the deviation from univariate normality does not affect the weighted least square estimators if the values of the items are below three in asymmetry and 10 in Kurtosis (Marôco, 2014), the univariate normality of the data was verified with the Kolmogorov-Smirnov test. Adequate values were obtained.

\section{Subscale descriptive statistics and latent correlation analyses}

As observed in Table 3, the intrinsic motivation means $(M=4.18)$ and identified regulation means $(M=4.25)$ were the highest, while the amotivation subscale $(M=$ 1.49) presented the lowest mean, followed by external regulation $(M=2.23)$. Likewise, the correlations between the nearest factors were significant and positive. With respect to latent correlations between opposing factors of the continuum (intrinsic motivation and amotivation), a stronger negative correlation was found $(r=-.73$, $p<.001$ ) than between other closer factors (intrinsic motivation and external regulation, $r=-.23, p<.001$ ).

\section{Measurement model: confirmatory factor analyses}

Multivariate normality was verified by means of the Mardia multivariate index, obtaining values that did not represent any critical disadvantage for the CFA. As observed in Table 4, the model $1^{2}$ did not show an adequate level of fit in all indices (RMSEA $=.121$ ).

\footnotetext{
${ }^{2}$ Model 1 of the EME-ES represents the five-factor CFA (i.e., intrinsic motivation, identified regulation, introjected regulation, external regulation and amotivation) with no interrelated items.
} 
Table 4. Fit Indices of the Models Analyzed

\begin{tabular}{lllllllll}
\hline Model/Test & $\chi^{2}$ & $d f$ & $p$ & $\chi^{2} / d f$ & RMSEA & CFI & TLI & ECVI \\
\hline Model 1 & 1360.797 & 142 & .001 & 9.583 & .121 & .922 & .906 & 2.702 \\
Model 2 & 762.227 & 129 & .001 & 5.483 & .080 & .960 & .951 & 1.688 \\
\hline
\end{tabular}

Note: $\chi^{2}=$ scaled chi-square test of exact fit; $d f=$ degrees of freedom; RMSEA = root mean square error of approximation; $\mathrm{CFI}=$ comparative fit index; TLI $=$ Tucker-Lewis index; ECVI $=$ expected cross-validation index.

Consequently, following the recommendations of Finney and DiStefano (2006), the fits were carried out in agreement with the modification indices. The highest values were observed among the item correlations of the same factors, respecting the five-factor structure. Thus, Items 5 and 8, 4 and 12, and 6 and 15, belonging to the factors of intrinsic motivation, introjected regulation and external regulation, respectively, were interrelated. Moreover, the wording of the correlated items presented notorious semantic similarities, which could support the modification choices. Finally, after analyzing the differences in ECVI between both models, Model 2 was accepted, as it significantly improved on the fit indices of Model 1.

\section{Multigroup confirmatory factor analyses}

The invariance of the EME-ES (Table 5) was verified with three multi-group CFA. In the first, participants were randomly divided into two homogeneous subsamples ( $n^{1}=$ even; $n^{2}=$ odd) with the same number of individuals (292). In the second, gender was selected as the criterion, and the sample was divided between male $(n=254)$ and female $(n=330)$. Finally, in the third, the type of school was used as the criterion, and the teachers were divided into state schools $(n=416)$ and non-state (associated and private) $(n=168)$. Three progressively more restrictive models were run for each of the three groups: (1) configural invariance; (2) metric invariance (i.e., invariance of factor loadings/crossloadings); and (3) strong measurement (i.e., invariance of factor loadings/cross-loadings, and intercepts).
The nested models were evaluated via consideration of changes $(\Delta)$ in goodness-of-fit indices, with increases in CFI and TLI of at least .010, indicating a lack of invariance (Cheung \& Rensvold, 2002). As observed in Table 5, configural and metric invariance did not exceed the cutoff recommendations in the three multigroup CFA for CFI $(\Delta>.01)$ or $\Delta \mathrm{TLI}(\Delta>.01)$. However, these cutoff recommendations were exceeded for the random odd and even subsamples, gender and type of school in the next step (i.e., strong invariance). Nevertheless, although full invariance for the EME-ES cannot be supported across random samples, gender, and type of school, partial invariance (i.e., configural and metric) may be sufficient condition for a meaningful cross-group comparison (Cheung \& Rensvold, 2002).

\section{Reliability}

As observed in Table 3, Cronbach's alpha values were acceptable in all factors $(\alpha>.70)$, with the exception of introjected regulation $(\alpha=.68)$. Although this value is very close to .70 , it can be considered acceptable due to the small number of items (i.e., four) that comprise it (Dunn, Baguley, \& Brunsden, 2014). CR values were satisfactory in all factors with results of over .70. With respect to AVE, acceptable values were obtained in all factors $(>.50)$, with the exception of introjected regulation $(\mathrm{AVE}=.39)$, although it was close to recommended values (Dunn et al., 2014). This could be explained by Item 8 , pertaining to introjected regulation, which presented a weak factor loading $(\beta=.28)$.

Table 5. Fit Indices of the Model Tested for the Invariance Analyses

\begin{tabular}{llllllllllc}
\hline Invariance analyses & Model & \multicolumn{1}{l}{$\chi^{2}$} & df & $p$ & $\chi^{2} / d f$ & RMSEA & CFI & TLI & $\Delta$ CFI & $\Delta$ TLI \\
\hline Odd and even & Configural invariance & 1037.56 & 330 & .001 & 3.14 & .08 & .958 & .957 & - & - \\
$\quad$ subsamples & Metric Invariance & 994.20 & 344 & .001 & 2.89 & .08 & .961 & .962 & +.003 & +.005 \\
Gender subsamples & Configural invariance & 1088.23 & 330 & .001 & 3.29 & .09 & .954 & .953 & - & - \\
& Metric Invariance & 1053.85 & 344 & .001 & 3.06 & .08 & .957 & .957 & +.003 & +.004 \\
Type of school & Configural invariance & 1019.14 & 330 & .001 & 3.08 & .08 & .950 & .948 & - & - \\
$\quad$ subsamples & Metric Invariance & 992.34 & 344 & .001 & 2.88 & .08 & .953 & .954 & +.003 & +.004 \\
\hline
\end{tabular}

Note: $\chi^{2}=$ scaled chi-square test of exact fit; $d f=$ degrees of freedom; RMSEA = root mean square error of approximation; $\mathrm{CFI}=$ comparative fit index; TLI = Tucker-Lewis index; $\triangle \mathrm{CFI}=$ change in comparative fit index. The latent factors of the EME-ES are based on Model 2 (see measurement model section). 


\section{Concurrent validity}

Latent correlation analyses

First, CFA factors representing work dedication and boredom were added to the CFA model for the EME-ES. As observed in Table 3, the latent correlations between work dedication and boredom at work with the EME-ES factors were consistent with SDT, with the exception of introjected regulation that did not significantly correlate to work dedication.

\section{Structural equation model}

Second, based on the hypothesized measurement model (Figure 1) of the EME-ES, the SEM of the scale was analyzed with the outcomes of work dedication and boredom at work. Following the recommendations of Marôco (2014), the goodness-of-fit indices were $\operatorname{good}\left(\chi^{2}=1176.221 ; d f=326 ; \chi^{2} / d f=3.608 ; p<.001\right.$; RMSEA $=.067 ; \mathrm{CFI}=.968 ; \mathrm{TLI}=.963)$. As observed in Figure 2, all EME-ES factors significantly explained one of the two outcomes, with the exception of identified regulation. The proposed model explained $71 \%$ of the work dedication variance and $69 \%$ of the boredom at work variance.

\section{Discussion}

The purpose of this study was to devise a scale (EME-ES) with adequate psychometric properties to assess motivation for teaching in Secondary Education teachers.
To our knowledge, this is the first study that, specifically in the secondary teacher work context of Aragon, has integrated the five-factor structure proposed by the SDT together with teachers' dedication and boredom at work. The first hypothesis put forward referred to the construct validity, while the second and third hypotheses responded to concurrent validity.

Regarding construct validity, it was put forward that the EME-ES would adapt to the five-factor structure, showing adequate psychometric properties. Thus, findings support the psychometric adaptation of the EME-ES within the secondary education work context of Aragon. Firstly, the item and subscale descriptive and correlation analyses showed the presence of the selfdetermination continuum in line with SDT. Correlations between adjacent factors (e.g., intrinsic motivation and identified regulation) were significant, strong and positive. In contrast, opposing factors (i.e., intrinsic motivation and amotivation) presented higher negative correlations than other closer regulations in the continuum (e.g., intrinsic motivation and external regulation). All of this seems to reinforce the correct translation and adaptation of the items of the EME-ES, as well as their adaptation to the factors with which they were identified. Secondly, the results of the CFA confirm the 19-item and five-factor structure, in agreement with the theoretical model proposed by the SDT. This five-factor model of self-determined motivation is consistent with those previously used in the teaching context in different countries (Fernet et al., 2012; Gorizidis \&

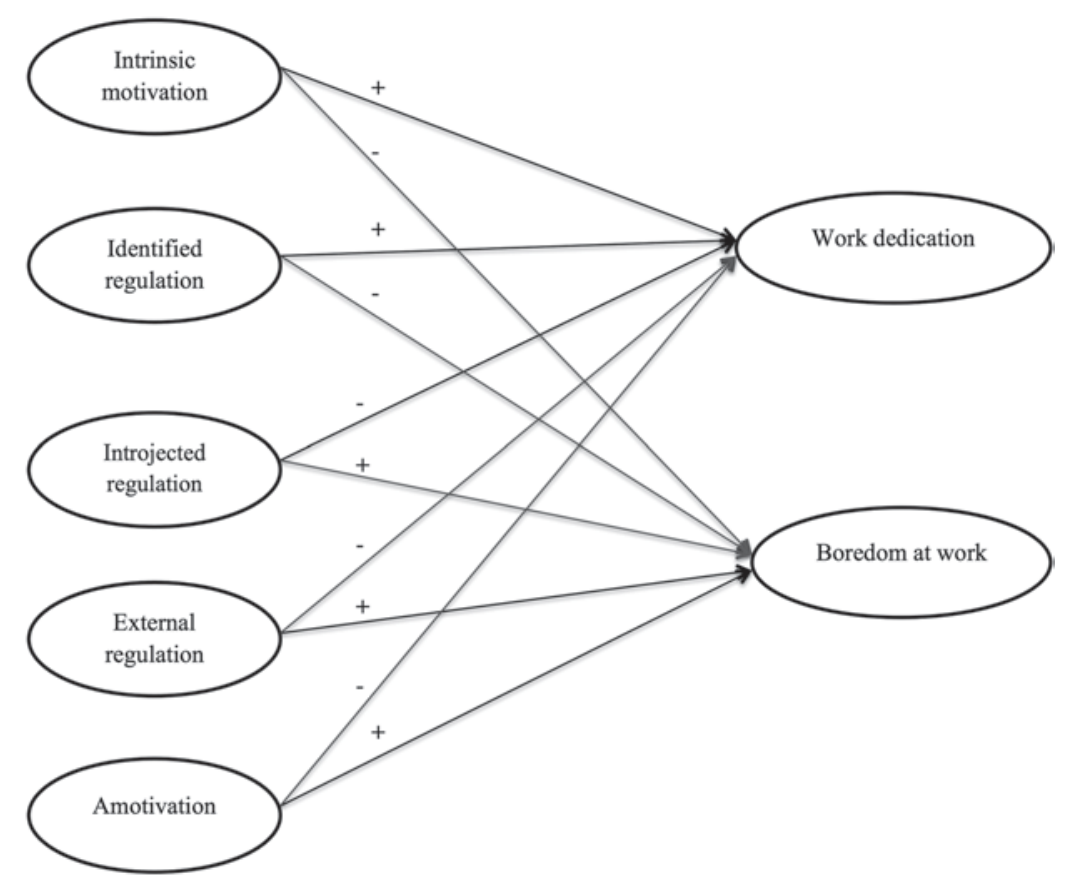

Figure 1. Hypothesized Structural Model of the EME-ES and Work Outcomes.

Note: Signs in relations between variables in agreement with the proposed hypotheses 


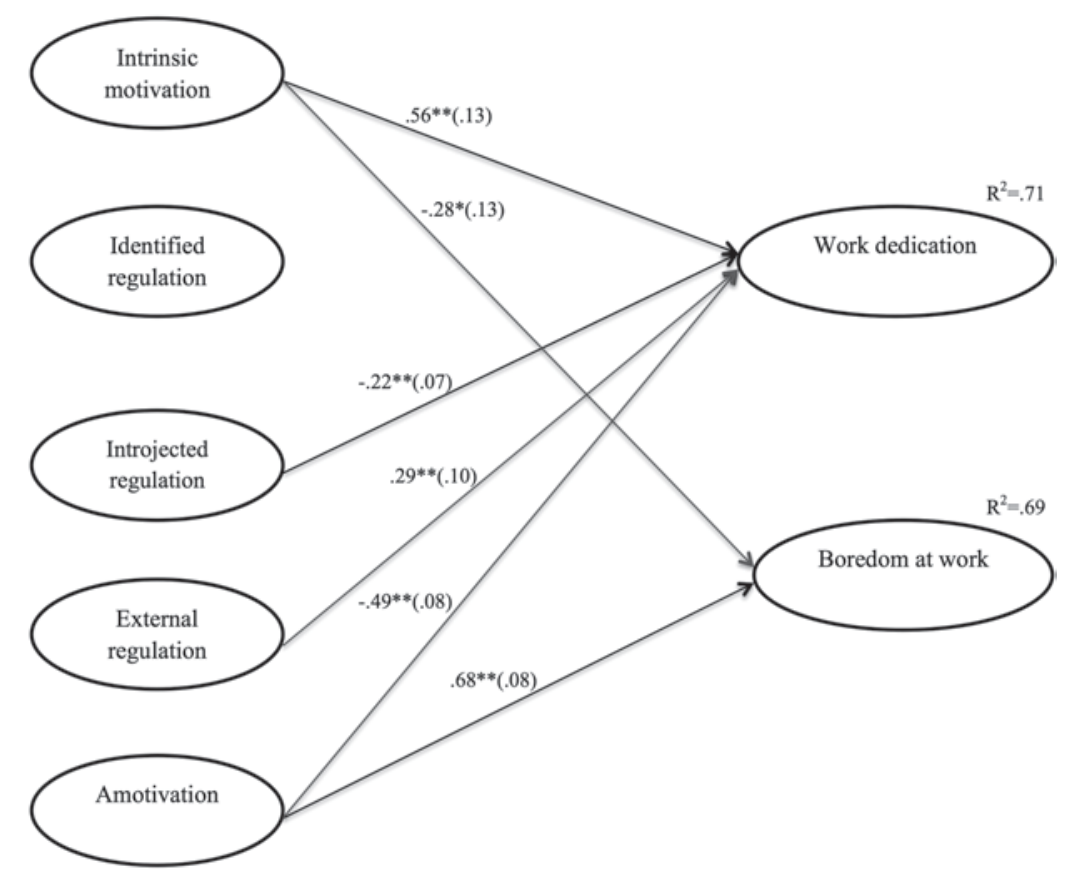

Figure 2. Structural Model of the EME-ES and Work Outcomes.

Note: ${ }^{*} p<.005 ;{ }^{* *} p<.001$; the standardized regression weight is over arrows; the standard error is reported in brackets; $R^{2}$ over latent variable; The latent factors of the EME-ES are based on Model 2 (see measurement model section)

Papaioannou, 2012) and more specifically in the Spanish teaching work context (Ruiz-Quiles et al., 2015). Thus, the indices reported by the EME-ES seem to establish the validity of the scale to evaluate the motivation of secondary education teachers because both RMSEA and CFI have adequate values.

Thirdly, the Cronbach's alpha values obtained in the EME-ES were acceptable in all factors, similarly to the WTMST in its Spanish version (Ruiz-Quiles et al., 2015). However, this parameter can be biased by the number of items used to calculate it (Dunn et al., 2014), so to palliate this bias, CR and AVE indices were provided in this study. These were acceptable, too, with the exception of the AVE introjected regulation value, which was, nevertheless, very close to recommended values. These adequate psychometric values could be explained because the EME-ES is designed for secondary education teachers, who possess distinguishing characteristics that could demand an individualized instrument to assess their motivation (Anaya \& López, 2014; Antoniou et al., 2013; Burke \& Greenglass, 1989; Otero-López et al., 2009). Finally, the three multi-group CFA present the EME-ES as a partially invariant (i.e., configural and metric) instrument in different samples of teachers, by gender and type of school. These findings are highlighted because of the influence that gender and type of school could have on teachers' motivation and other work outcomes (Fernet et al., 2008; Gil-Flores, 2016; Nie et al., 2015).
With respect to concurrent validity, it was put forward that more self-determined forms of motivation would significantly and positively explain work dedication, and significantly and negatively explain boredom at work, while less self-determined forms of motivation and amotivation would explain these outcomes in the opposite direction. The results of the latent correlations analyses showed strong and significant correlations between the majority of the motivational regulations of the EME-ES and work dedication and boredom at work, based on the tenets of SDT. These findings are consistent with other research studies that have positively associated more self-determined forms of motivation with teaching engagement (Cheon et al., 2014), comprised, among other factors, of work dedication. Likewise, Collie, Shapka, Perry and Martin (2016) showed a positive relationship between intrinsic motivation for teaching and enjoyment of the teaching activity. This variable is considered to be the opposite to boredom at work (Montero-Marín \& García-Campayo, 2010). Likewise, other studies on motivation for teaching indicate that intrinsic motivation and identified regulation are positively related to job satisfaction and teachers' self-efficacy (Fernet et al., 2008; RuizQuiles et al., 2015), and negatively related to teachers' exhaustion (Fernet et al., 2008; Fernet et al., 2012). Consistent with our results, past studies have shown that introjected and external regulation are positively related to teachers' exhaustion and positively related 
to teacher's self-efficacy (Fernet et al., 2008). Finally, Dörnyei and Ushioda (2011) pointed out that teachers' amotivation may be caused by the repetitive routine of contents, leading to boredom at work.

With respect to the SEM, the goodness-of-fit indices were adequate. However, the hypotheses put forward were partially met as some outcomes of motivation for teaching were not significantly explained by all the motivational regulations. As set forth, and in line with other studies that explained similar variables (Eyal \& Roth, 2011), intrinsic motivation positively explained work dedication and negatively explained boredom at work, while amotivation did the opposite. Likewise, introjected regulation, as a less self-determined form of motivation, was negatively related to work dedication. In contrast, in the structural model, we found an unexpected positive relationship between external regulation and work dedication, although latent correlations between manifest variables were opposing. This association could be explained by the importance that external reasons, such as pressure and expectations of headmasters and colleagues, may have on the actual work dedication. To illustrate this, some teachers might perceive the pressure placed on them by headmasters or colleagues, as an effort made by these agents to do some activities or to take part in interdisciplinary projects that would improve the students' learning process and that would, at the same time, stimulate them to improve their teaching. Under those particular circumstances, the pressure placed by headmasters or others teachers may even be interpreted as stimulating and encouraging for their work dedication. In this vein, other studies have indicated that a profile with a high quantity of motivation, characterized by high levels of more self-determined forms of motivation and also high levels of less self-determined forms of motivation, may facilitate positive outcomes such as acting as a buffer to burnout (van den Berghe et al., 2014). However, more studies are considered necessary to analyze the motivational profiles, adopting a person-centered approach, and other outcomes in this group to obtain a more solid explanation to the findings.

Finally, contrary to our hypothesis, identified regulation did not significantly explain either of the two outcomes that were introduced in the model. A possible explanation is that teachers may get involved in teaching due to personal and/or vocational choices and according to their individual values. These reasons could turn their work into a lifestyle, keeping the teachers' minds off the different challenges (dedication) and routines (boredom) that their work may represent on a daily basis. However, more research on the topic seems necessary. Another possible justification could be found in latent correlations, where intrinsic motivation was highly correlated with identified regulation.
This could suggest a discriminant validity problem justified by the high vocational character of teaching work as suggested by past studies with identified regulation (e.g., Roth et al., 2007). Thus, the inclusion of qualitative techniques such as interviews or observing teaching behavior could contribute to establishing relations between some, until now more unknown, variables in this group. All of this would make it easier to obtain a more complete overview of motivation for teaching (Han \& Yin, 2016). However, the represented model explains a high percentage of both outcomes, supporting the concurrent validity of the EME-ES. All of this reinforces the use of the EME-ES as an instrument that has a certain capacity to explain some outcomes related to the motivation of secondary education teachers.

Some limitations and perspectives should be taken into consideration. It must be pointed out that, in relation to the sample of the present study, full invariance for the EME-ES could not be supported. As new avenues of research, future studies should test full invariance again and should compile longitudinal data to be able to assess the time stability of the scale. Importantly, the SEM was conducted with crosssectional data and causality in relationships cannot be inferred. Moreover, more research on less selfdetermined forms of motivation seems to be needed in order to assess their impact on different work outcomes. Previous studies suggested that teachers could combine several reasons to teach (van den Berghe et al., 2014). It would be interesting to establish teachers' motivational profiles to analyze how resulting profiles differ in outcomes such as dedication and boredom at work. In addition, the relationship shown between external regulation and dedication to work in latent correlations is not congruent with the SEM findings. Perhaps in the future, other studies could analyze this relationship across longitudinal designs to try to explain if dedication should be interpreted as an outcome or as an antecedent of motivation for teaching.

To conclude, the EME-ES presents adequate psychometric properties, reliability and partial invariance across gender and type of school to assess motivation for teaching in secondary education teachers from the Aragon district-territory. In addition, concurrent validity findings of this study could increase knowledge about the relevance of motivation for teaching in several outcomes related to well-being at work.

\section{References}

Anaya D., \& López E. (2014). Satisfacción laboral del profesorado en 2012-13 y comparación con los resultados de 2003-04. Un estudio de ámbito nacional [Spanish teachers' job satisfaction in 2012-13 and comparison with 
job satisfaction in 2003-04. A nationwide study]. Revista de Educación, 365, 96-121. https:/ / doi.org/10.4438/1988592X-RE-2014-365-266

Antoniou A. S., Ploumpi A., \& Ntalla M. (2013). Occupational stress and professional burnout in teachers of primary and secondary education: The role of coping strategies. Psychology, 4(3), 349-355. https:/ / doi.org/ 10.4236/psych.2013.43A051

Ayman R., \& Korabik K. (2010). Leadership: Why gender and culture matter. American Psychologist, 65(3), 157-170. https://doi.org/10.1037/a0018806

Blais M. R., Lachance L., Vallerand R. J., Briere N. M., \& Riddle A. S. (1993). The work motivation inventory. Revue Quebecoise de Psychologie, 14, 185-215.

Burke R. J., \& Greenglass E. R. (1989). Psychological burnout among men and women in teaching: An examination of the Cherniss model. Human Relations, 42(3), 261-273. https: / / doi.org/10.1177/001872678904200304

Cheon S. H., Reeve J., Yu T. H., \& Jang H. R. (2014). The teacher benefits from giving autonomy support during physical education instruction. Journal of Sport \& Exercise Psychology, 36(4), 331-346. https:/ / doi.org/10.1123/jsep. 2013-0231

Cheung G. W., \& Rensvold R. B. (2002). Evaluating goodness-of-fit indexes for testing measurement invariance. Structural Equation Modeling: A Multidisciplinary Journal, 9(2), 233-255. https:/ / doi.org/10.1207/ S15328007SEM0902_5

Collie R. J., Shapka J. D., Perry N. E., \& Martin A. J. (2016). Teachers' psychological functioning in the workplace: Exploring the roles of contextual beliefs, need satisfaction, and personal characteristics. Journal of Educational Psychology, 108(6), 788-799. https://doi.org/10.1037/ edu0000088

Deci E. L., \& Ryan R. M. (1985). Intrinsic motivation and self-determination in human behavior. New York, NY: Plenum.

Dörnyei Z., \& Ushioda E. (2011). Teaching and researching motivation ( $2^{\text {nd }}$ ed.). New York, NY: Longman

Dunn T. J., Baguley T., \& Brunsden V. (2014). From alpha to omega: A practical solution to the pervasive problem of internal consistency estimation. British Journal of Psychology, 105(3), 399-412. https:/ / doi.org/10.1111/bjop.12046

Eyal O., \& Roth G. (2011). Principals' leadership and teachers' motivation: Self-determination theory analysis. Journal of Educational Administration, 49(3), 256-275. https:/ / doi.org/10.1108/09578231111129055

Fernet C., Guay F., Senécal C., \& Austin S. (2012). Predicting intraindividual changes in teacher burnout: The role of perceived school environment and motivational factors. Teaching and Teacher Education, 28(4), 514-525. https://doi.org/10.1016/j.tate.2011.11.013

Fernet C., Senécal C., Guay F., Marsh H., \& Dowson M. (2008). The Work Tasks Motivation Scale for Teachers (WTMST). Journal of Career Assessment, 16(2), 256-279. https: / / doi.org/10.1177/1069072707305764

Finney S. J., \& DiStefano C. (2006). Nonnormal and categorical data in structural equation modeling. In G. R. Hancock \& R. O. Mueller (Eds.), Structural equation modeling: A second course (pp. 269-314). Greenwich, CO: Information Age Publishing.
Gil-Flores J. (2016). The role of personal characteristics and school characteristics in explaining teacher job satisfaction. Journal of Psychodidactics, 22(1), 16-22. https:/ / doi.org/ 10.1387/RevPsicodidact.15501

Gorozidis G., \& Papaioannou A. (2012, May). Initial validation of the "Work Tasks Motivation Scale for Teachers" - Greek version (WTMST-GR). Paper presented at the $20^{\text {th }}$ International Conference of Physical Education and Sports. Komotini, Greece.

Gorozidis G., \& Papaioannou A. G. (2014). Teachers' motivation to participate in training and to implement innovations. Teaching and Teacher Education, 39, 1-11. https://doi.org/10.1016/j.tate.2013.12.001

Han J., \& Yin H. (2016). Teacher motivation: Definition, research development and implications for teachers. Cogent Education, 3(1), 1217819. https://doi.org/10.1080/ 2331186X.2016.1217819

Høigaard R., Giske R., \& Sundsli K. (2012). Newly qualified teachers' work engagement and teacher efficacy influences on job satisfaction, burnout, and the intention to quit. European Journal of Teacher Education, 35(3), 347-357. https:/ / doi.org/10.1080/02619768.2011.633993

Joe H. K., Hiver P., \& Al-Hoorie A. H. (2017). Classroom social climate, self-determined motivation, willingness to communicate, and achievement: A study of structural relationships in instructed second language settings. Learning and Individual Differences, 53, 133-144. https:/ / doi.org/10.1016/j.lindif.2016.11.005

Kinman G., Wray S., \& Strange C. (2011). Emotional labor, burnout and job satisfaction in UK teachers: The role of workplace social support. Educational Psychology, 31(7), 843-856. https:/ / doi.org/10.1080/01443410.2011.608650

Latorre I., \& Sáez J. (2009). Analysis of burnout in nonuniversity professors in the Region of Murcia (Spain) depending on the type of school: Public versus private. Annals of Psychology, 25, 86-92.

Lukaszewski K. M., \& Stone D. L. (2012). Theory and research on social issues in organizations. Journal of Managerial Psychology, 27(4), 324-329. https://doi.org/ $10.1108 / 02683941211220216$

Marôco J. (2014). Análise de equações estructurais. Fundamentos teóricos, software \& aplicações [Analysis of structural equations: theoretical fundamentals, software, and applications] ( $2^{\text {nd }}$ ed.). Pero Pinheiro, Portugal: Report Number.

Montero-Marín J., \& Garcia-Campayo J. (2010). A newer and broader definition of burnout: Validation of the "burnout clinical subtype questionnaire (BCSQ-36)". BMC Public Health, 10(1), 302-310. https:/ / doi.org/ 10.1186/1471-2458-10-302

Muñiz J., Elosua P., \& Hambleton R. K. (2013). Directrices para la traducción y adaptación de los tests: Segunda edición [International Test Commission guidelines for test translation and adaptation: second edition]. Psicothema, 25(2), 151-157. https://doi.org/10.7334/ psicothema2013.24

Nie Y., Chua B. L., Yeung A. S., Ryan R. M., \& Chan W. Y. (2015). The importance of autonomy support and the mediating role of work motivation for well-being: Testing self-determination theory in a Chinese work organization. 
International Journal of Psychology, 50(4), 245-255. https:/ / doi.org/10.1002/ijop.12110

Otero-López J. M., Castro C., Villardefrancos E., \& Santiago M. J. (2009). Job dissatisfaction and burnout in secondary school teachers: student's disruptive behavior and conflict management examined. European Journal of Education and Psychology, 2(2), 99-111.

Pelletier L. G., Séguin-Lévesque C., \& Legault L. (2002). Pressure from above and pressure from below as determinants of teacher's motivation and teaching behaviors. Journal of Educational Psychology, 94(1), 186-196. https:/ / doi.org/10.1037/0022-0663.94.1.186

Roth G., Assor A., Kanat-Maymon K., \& Kaplan H. (2007). Autonomous motivation for teaching: How selfdetermined teaching may lead to self-determined learning. Journal of Educational Psychology, 99(4), 761-774. https:/ / doi.org/10.1037/0022-0663.99.4.761

Ruiz-Quiles M., Moreno-Murcia J. A., \& Vera J. A. (2015). Del soporte de autonomía y la motivación autodeterminada a la satisfacción docente [The support of autonomy and self-determined motivation for teaching satisfaction]. European Journal of Education and Psychology, 8(2), 68-75. https:/ / doi.org/10.1016/j.ejeps.2015.09.002

Ryan R. M., \& Connell J. P. (1989). Perceived locus of causality and internalization: Examining reasons for acting in 2 domains. Journal of Personality and Social Psychology, 57(5), 749-761. https://doi.org/10.1037/0022-3514.57.5.749

Schaufeli W. B., Martínez I. M., Marques-Pinto A., Salanova M., \& Bakker A. B. (2002). Burnout and engagement in university students: A cross-national study. Journal of Cross-Cultural Psychology, 33(5), 464-481. https: / / doi.org/10.1177/0022022102033005003

Soenens B., Sierens E., Vansteenkiste M., Dochy F., \& Goossens L. (2012). Psychologically controlling teaching:
Examining outcomes, antecedents, and mediators. Journal of Educational Psychology, 104(1), 108-120. https://doi.org/ $10.1037 / \mathrm{a} 0025742$

Thoonen E. E. J., Sleegers P. J. C., Oort F. J., Peetsma T. T. D., \& Geijsel F. P. (2011). How to improve teaching practices: The role of teacher motivation, organizational factors, and leadership practices. Educational Administration Quarterly, 47(3), 496-536. https://doi.org/10.1177/ $0013161 X 11400185$

Tremblay M. A., Blanchard C. M., Taylor S., Pelletier L. G., \& Villeneuve M. (2009). Work Extrinsic and Intrinsic Motivation Scale: Its value for organizational research. Canadian Journal of Behavioural Science, 41(4), 213-226. https:/ / doi.org/10.1037/a0015167

van den Berghe L., Soenens B., Aelterman N., Cardon G., Tallir I. B., \& Haerens L. (2014). Within-person profiles of teachers' motivation to teach: Associations with need satisfaction at work, need-supportive teaching, and burnout. Psychology of Sport and Exercise, 15(4), 407-417. https://doi.org/10.1016/j.psychsport.2014.04.001

Vansteenkiste M., Sierens E., Soenens B., Luyckx K., \& Lens W. (2009). Motivational profiles from a selfdetermination perspective: The quality of motivation matters. Journal of Educational Psychology, 101(3), 671-688. https://doi.org/10.1037/a0015083

Viseu J., de Jesus S. N., Rus C., \& Canavarro J. M. (2016). Teacher motivation, work satisfaction, and positive psychological capital: A literature review. Electronic Journal of Research in Educational Psychology, 14(2), 439-461. https://doi.org/10.14204/ejrep.39.15102

Watt H. M. G., \& Richardson P. W. (2015). Teacher Motivation. In J. D. Wright (Ed.), International Encyclopedia of the Social \& Behavioral Sciences (pp. 64-71). Oxford, UK: Elsevier. 